\title{
ICT-supported for participatory engagement within E-learning community
}

\author{
Noor Hida Natrah Aziz, Haryani Haron, Afdallyna Fathiyah Harun \\ Faculty of Computer \& Mathematical Sciences, Universiti Teknologi MARA, Malaysia
}

\begin{tabular}{l}
\hline \hline Article Info \\
\hline Article history: \\
Received Feb 4, 2020 \\
Revised Apr 8, 2020 \\
Accepted Apr 22, 2020 \\
\hline
\end{tabular}

\section{Keywords:}

E-learning

E-learning community

Learners' engagement

Participatory engagement

Participatory learning

\begin{abstract}
This paper presents ICT-supported for participatory engagement learning within the e-learning community. The selection of effective tools in eLearning is crucial to supports interactive learning and able to achieve of desired learning outcomes. However, the intensity of its usage is not very remarkable; there is a need to understand ICT- supported for learners from the perspectives of participatory engagement. Therefore, integrating suitable technology into e-learning is expected to strengthen learner's engagement within the e-learning community. The objective of the study is to identify technology that could effectively support learners' engagement. This study analyzes the available technology in the market to integrate into e-learning using the technology evaluation process. Interview sessions with experts were held to validated and suggested other technology uses in e-learning. This research is carrying out with three experts (academic staff) of the etechnologies within the University. This study uses semi-structured interviews to captured expert suggestions, knowledge, and expertise about technologies. Understanding learner's requirements toward technology are essential to ensure learners can reap the benefits of technology usage. This study uses a thematical analysis to identify and organize key themes from qualitative data. The result reveals mobile technology, wireless technology, live streaming technology, authoring tool, summative assessment, cloud computing, gamification and Instagram is suitable technologies that support participatory engagement activities. .
\end{abstract}

Copyright $(2020$ Institute of Advanced Engineering and Science. All rights reserved.

\section{Corresponding Author:}

Haryani Haron,

Faculty of Computer \& Mathematical Sciences,

Universiti Teknologi MARA,

40450 Shah Alam, Selangor, Malaysia.

Email: Haryani@tmsk.uitm.edu.my

\section{INTRODUCTION}

Interaction is the main element that requires for successful learning in e-learning [1]. In the e-learning environment, three fundamental interactions took place, which is learner to learner, educator to the learner, and learner to content [2]. Among these three interactions, [3, 4] found out that learner to learner interaction is the most desirable interaction and significantly impacted learners' achievement in learning. The interaction itself consider as communication practice represents an essential stage in transferring knowledge [5] and increase learner participation in e-learning [6]. Social interaction provides dynamic engagement for learners to acquired knowledge. It expands their learning skills learners perceive their interaction with educators and peers in gaining supports, ready for open communication, responsiveness, and presence of educators in learning [5]. It has led to social learning activities increasing interest in the development of online communities in e-learning [7]. An online community is defining as groups of people who are connected via technology-mediated communication, who actively engage one another in collaborative learner-centered activities to intentionally foster the creation of knowledge while sharing several values and practices [8]. 
It creates a platform to collaborate and an environment that encourages learners to participate in the e-learning community to interact and collaborate [9]. The frequent interaction among peers in e-learning led to engagement and is usually associated with learner achievement in learning [10]. Engagement is seen as willingness actions for learners involvement with and effort in the learning process and learners' positive emotions towards the subject [11]. Thus, learner's engagement is seen as an essential element to improve learners' achievements.

Over the past decade, different ICT advancement has grown and has supported the way people learns and interacts. The rapid development of ICT (Information and Communication Technology) has embraced many researchers to be a concern on how advancing technology to facilitate interactive processes in communication, including e-learning [12]. Technological tools that emphasize interaction frequently insert asynchronous features, such as e-mail, and synchronous methods, such as chat and streaming media facilities [5]. Besides that, other technology support interactions, including social media, wiki, web 2.0, have an open door for an enormous degree of interactions [13]. Besides that, the usage of mobile devices in accessing has hugely transformed the learning landscape [14]. The usage of mobile providing the learner with the opportunity of flexsibility, learning independent of time and location and created dinamically and communication with others [15]. However, engaging learners for active participation in the learning process is an essential yet challenging pedagogical issue across disciplines. From an analysis of the current literature, this study found the problem appear about the e-learning community. Learners in the e-learning platform tend to learn in isolation, lacks communication and collaboration, and rarely felt of other presence in the e-learning community that could lead to disengagement learning [16, 17]. To address this challenge, this study proposing suitable ICT for participatory engagement within the e-learning community. In response to the need for ICT resources could effectively improve online interaction within e-learning, this study proposes present ICT supported for participatory engagement using the technology evaluation process.

\section{LITERATURE REVIEW}

\subsection{Participatory learning}

The theory of participatory learning is idea that learners able to achieve better results if the learning process "reproduces, or runs parallel to, some form of work carried on in social life" [18]. According to [19], participatory learning as "learners are active participants or co-producers rather than passive consumers of content, and... learning is a participatory, social process supporting personal life goals and needs". Participatory learning involves active learners and personalize learning [20] based on problem-solving style [18] and learners engage in learning community [21]. Meanwhile [22], classified participatory learning is learning based on experience through collaborative learning, co-learning and engagements in a community. Participatory learning is encouraging knowledge socially constructed among the learner to by participate in active learning, by being co-producers rather than passive consumer of content [18-20] and construct artefacts, [18-19, 21]. Due to this pursuance of constructionism, learning context is involved collaboration that requires learners collaborate to create artefacts $[18,20-21]$. The learning activites at learning community creates a platform for learners to produce artefacts that contribute to the community of learners. In the participatory learning environment, learners are actively constructing their new knowledge and deepen understanding through interaction with other learners within the e-learning community [18, 21]. Thus, participatory learning emphasis learner empowerment, educator's roles have changed from controlled learning process to monitoring or guiding along the learning process [18].

\subsection{Participatory engagement}

Drawing some extent of participatory learning, a previous study [22] introduce participatory engagement based on participatory learning theory to support learner's engagement. Engagement is undeniable as the crucial elements in educations because it has a favourable implication in learning [23, 24]. Engagement viewed as active participation in the learning process which contributes to deeper and more meaningful learning and consistently be factor influence learner's performance in e-learning. The engagement is vital in learning because learners become pay more attention and to show more interest and persistence when facing challenges than their disengaged peers [25]. To enhance participatory learning activities in e-learning, in previous study, the researcher has suggested participatory engagement components. Figure 1 presents a conceptual of participatory engagement concept of interconnected elements that derive their full meaning concerning each other [22].

Based on Figure 1 above, the participatory engagement components were consisting of four (4) components which are interaction, collaboration, feedback and self-reflection [22]. The aims of participatory engagement are strengthening learner' engagement by paying attention to the interactions of learners, collaborations between diverse background of learners, active participation, social learning and constructionism. The Figure 1 highlights the interaction of learners as primary interaction in participatory engagement. 
The interaction of learners is two-way reciprocal communications between learners and learners. The interaction has formed with symbiotic relationships whereby learners are mutually influencing and improving each other knowledge. Next component of participatory engagement is collaboration. Collaboration is that two or more learners are working together to reach the same learning goals. Learners in the e-learning community are together in completing tasks given or creates artefacts and contribute to the e-learning community. Subsequently, is feedback being an action to the response to other questions or comments for improvement. This is important to evaluate learners' understaning about subject. The last component is self-reflection which is critical thoughts produce when the other three components take place in the learning. Learners write their critical thoughts or experience throughout the learning process as a learning record [22].

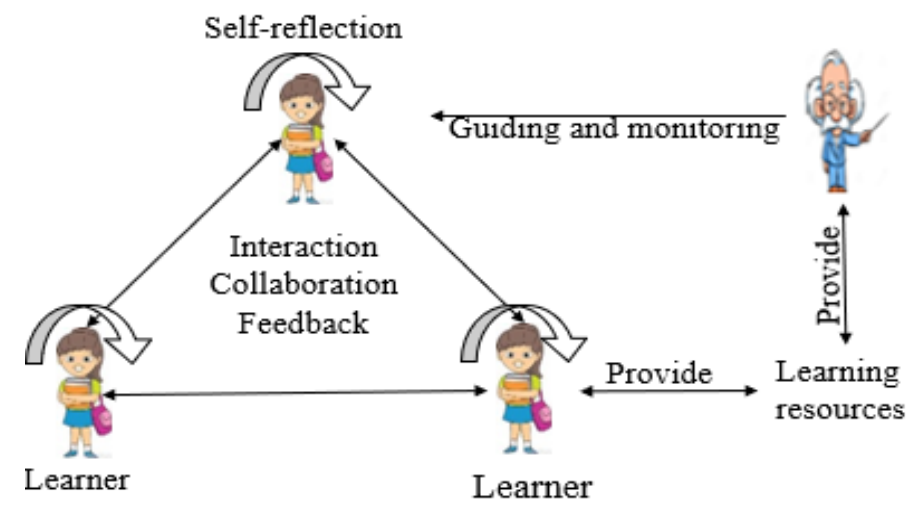

Figure 1. Conceptual model of participatory engagement within e-learning community [22]

\subsection{E-learning and technologies}

Vast development in ICT has turn ICT to be participatory to supports social learning and collaborative. There are numerous numbers of participatory technology such as web 2.0 [22, 26], social media, wiki [27], audio or text-based blog, audio, forum, video conferencing in virtual learning community experience are extensively applied to support participatory learning [27-29]. This technology supports interaction of learners involve into social environment, frequent interactions and knowledge are socially constructed [9, 29]. Besides, mobile technology and wireless technology that are becoming widespread have contributed to accessibility and instance, access to e-learning [30]. Furthermore, e-learning allowed learners to participate regardless of location in timeliness removed geographical barriers and increase efficiency in time. Thus, above, the participatory engagement components.

\section{METHODOLOGY}

Next, this research moved from a literature review to the technology evaluation process. The technology evaluation process includes the identification of experts. The identification of experts aims to validate and suggest suitable technology. The method technology evaluation process uses proposed by [31] was adopted. Figure 2 illustrated the technology evaluation process that was used in this study.

\subsection{Evaluation and selection process}

This study carried out the evaluation and selection process from [31]. The aims of evaluation and selection technology firstly are exploring the current technology available and secondly to map the selected technologies with participatory engagement components. Figure 2 shown a process evaluation and selection process. The details of the process are detailed, explain below:

\subsubsection{Step 1: define functional criteria}

In this study, the researcher requires participants to establish the functional criteria for technology. The functional criteria are developed to supports previous work [22]. The aims establish the functional criteria to address related to the functions performed by the system concerned with how things will function from a user's perspective. Functional criteria are used to supported by technology has selected. The output is a list of functional criteria that supports participatory engagement activities. 


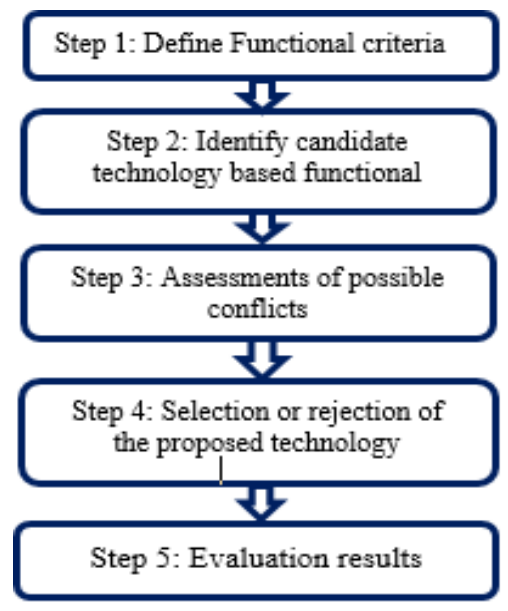

Figure 2. Technology evalaution process [31]

\subsubsection{Step 2: identify candidate technology-based functional criteria}

Based on the functional criteria defined in Step 1, the researcher identifies and listed suitable candidate technology in the market, which matched with functional criteria in Step 1. For certain functional criteria, it probably has more than one technology which suitable to candidate technology that requires experts for resolving the conflicts. Thus, the expertise of experts forms various field were sought.

\subsubsection{Step 3: assessments of possible conflicts}

The researcher puts the list of functional criteria and candidate technology as an interview question. Based on the set of interview questions, the experts assess the impact of the listed candidate technology on the functional criteria. In this step, the researcher can define some possible conflicts with other technologies used. The output of this stage is a list of functional standards and candidate technology. The list of experts was chosen is a senior lecturer who are with Ph.D. holder at UiTM Shah Alam. The primary data collection method is the interview. The interview conducted was semi-structured, in-depth and face to face nature. The interviews lasted between 30-60 minutes and were audio-recorded and transcribed for analysis. Before the interview started, the experts were briefly explained about the purposes of the interview session and were given a set of interview questions. The interview question was develop based on [15]. The selection process considers several criteria such as arrays of experience in e-learning background, publications, and research. The selection of validates and suggested technology captured through an interview session [24]. These experts are conveniently accessible to the researcher, and more importantly, they possess excellent knowledge and experience in handling the e-learning community. The interview sessions and conversation are permitted to be recorded. At the end of the interview session, the researcher collected the interview questions.

\subsubsection{Step 4: selection or rejection of the proposed technology}

In Step 4, the experts are repeating in potential review steps 2 and 3 until experts are satisfied with the technology to be selected. After the assessment of the possible conflict carried out on the candidate technologies, the researcher decided to choose the following technologies to be used to support the participatory engagement as recommended by the experts. The output of this stage is a list of technologies selected is presented in the evaluation result in the following section.

\subsubsection{Step 5: evaluation results}

Finally, the results of the technology evaluation were listed and presented in in Table 1.

\section{FINDING AND ANALYSIS}

In researcher previous study, reseracher found that the participatory engagement to improve and enhance learners engagement in the e-learning community [22]. Based on the previous work findings, four components in participatory engagement was found and has been named i. Interaction, ii. Collaboration, iii. Feedback and iv. Reflection. Next, reseracher expand the study and identify suitable technology that able to support participatory engagement within e-learning community. Based on the findings, this study discovered a list of technology can support participatory engagement within e-learning community. The findings were illustrated in Table 1 shows a list the technology suggested and the fuctions works to supports participatory engagement. 
Table 1 summarized suggested technology that able to supports participatory engagement. Based on the fuctional criteria, the interview able to discover suitable technology to supports participatory engagement. The fuctions of technology are stated to clarify on how the technology able to supports participatory engagement.

Table 1. Technology selected to supports participatory engagement with e-learning community

\begin{tabular}{|c|c|c|}
\hline $\begin{array}{l}\text { Participatory } \\
\text { Engagement }\end{array}$ & Technology suggested & Functions \\
\hline \multirow[t]{4}{*}{ Interaction } & Mobile devices Wreless & Supports learning at any time from anywhere. \\
\hline & Live streaming & Two-way reciprocal communication in real-time, live, simultaneous. \\
\hline & Create a new session & Learners can a create new session for self-learning \\
\hline & Invitation & Presence of educators and expert \\
\hline \multirow[t]{4}{*}{ Collaboration } & Chat & $\begin{array}{l}\text { Learners from the heterogeneous background are socially collaborated to achieve } \\
\text { mutual agreement. }\end{array}$ \\
\hline & Authoring tool & $\begin{array}{l}\text { Learners and peers working together as co-worker contribute their specialist through } \\
\text { collaborative writing. }\end{array}$ \\
\hline & Invitation & Experts participate in collaborative writing to produce quality content work together. \\
\hline & Notification & To notify any changes to in collaborative writing. \\
\hline \multirow[t]{6}{*}{ Feedback } & Summative assessment & $\begin{array}{l}\text { Participants provide adequate feedback for useful, constructive and quality feedback } \\
\text { in writing. }\end{array}$ \\
\hline & Reply post & Peers provide specific explanation and one to one basis feedback. \\
\hline & Invitation & Experts/educators provide quality feedback and improve accurately. \\
\hline & Notification & Notify any new updates to provide timely manner feedback for each question. \\
\hline & Gamification & Peers are reviewing and evaluate learner works. \\
\hline & Cloud technology & To support dynamic and on demands at the flexible time from anyplace. \\
\hline \multirow[t]{3}{*}{ Self-reflection } & Comment & Experts are participating in discussion and learners and have fruitful discussions. \\
\hline & Instagram & Learners are recorded learning progress or write any critical thoughts. \\
\hline & Write post & Learners share their reflective thoughts and learning experience with others. \\
\hline
\end{tabular}

\subsection{Mobile technology and wireless technology}

Firstly, the study found out the uses of mobile technology allows learners to facilitate learning anywhere and anytime, turn to learn to be flexible and convenient. This study identified mobile device is the primary devices used to access e-learning. The uses of the mobile device are portable communication system, to ease the learning by allowing learner access e-learning timeliness without distractions or ubiquitously [32]. Furthermore, the mobile device provides for responsiveness, encourage social interaction and portability. Mobile device andcomplementary with wireless technology allowed learners to access E-learning whenever required. Wireless technology allowed learners accessing to mass information, ubiquity content and facilitating networking whenever they need [33].

\subsection{Live streming technology}

Secondly, this study identified live streaming technology that supports the interaction of learners in e-learning community. The characteristic of live streaming technology supports two-way reciprocal communication with multiple learners engage in live, real-time simultaneous [33] is expected to encourage interaction, allowing learners to perceive the presence of others. In live streaming, viewers of live video can also communicate and involved with the broadcaster (or streamer), by chatting to share their knowledge and with other viewers and builds social relationships [34]. In addition, the streamer can invite anyone into their live sessions to interact and collaborate with selected learners. Besides that, every user can create their content or participate in other viewers' live video streams. By creating their content or topic, learners have a high degree of autonomy and self-regulated. Furthermore, learners/ expert facilitated a live session using live streaming technology, and learners can get useful and quality knowledge from experts. Learners were encouraged to reflect, interact, and undertake knowledge creation, based upon the topics generated by this session and the comments and views of other participants, including the facilitators. Plus, if any learners are unable to participate live session, the live streaming can be recorded for later retrieval whenever needed [35].

\subsection{Authoritng tools}

Subsequently, this study suggests authoring tools to supports collaboration. Authoring tools allow multiple learners to engage editing in live on the production of shared materials where learners engage substantive and shared responsibility for the document. Authoring tools also can be accessed at any time from anywhere for flexibility to create content from a mobile device, tablets seamlessly for flexibility in editing document. Besides that, the selection of participants is essential to shape the types of knowledge to produce.

The pooling of diverse abilities form experts, along with the learners as a co-worker, contribute their specialist through collaborative writing to produce quality content work together. Thus, it is necessary to invite others to participate in accomplishing the tasks. During achieving the tasks, communication among learners is vital such as 
interact with others, receive feedback from educators, experts for fruitful collaboration and improve the learning content provided to the academic community. It also helps to improve their writing skills to a greater extent than what they could achieve individually [36]. Besides that, it even able to notice any changes to in collaborative writing.

\subsection{Summative assessment}

Next, this study suggests the uses of summative assessment in assessing learners' understanding. The purpose of a summative assessment in eLearning is to get feedback on their performance along the course or learning [37]. The implementation of summative assessment in e-learning gives invaluable data to use to improve future learning. The summative assessment selected because it could support great feedback for enough feedback. The assessment evaluates by experts/educators to provides quality and accurate feedback. In the delivery of the feedback, learners are valuable adequate feedback such useful, specific, constructive, quality feedback. Other than that, leaners prefer one to one basis feedback specifically for themselves instead of general feedback. Learners are expecting to receive the feedback promptly and reduce waiting time. It included notification so that learners are aware of any latest input given to them.

\subsection{Gamification}

Based on findigs, this study proposes uses of gamification element in summative assessment to better learn outcomes. Gamification is a technique where insert gameplay elements in non-gaming settings so as to enhance user engagement with a product or service. This is inline with previous study [38] that stated he use of gamification for assessment reveals the merits is possible for gamification to be an option in assessing learners. Peer assessment is uses as tool to evaluating students' understanding as well as providing them with a fun review, thus study suggests badges as tokens that appear as icons to signify an individual's achievements. This allows encourage learners take it as serious tasks to produce better and quality feedback.

\subsection{Cloud storage}

The finding shows the massive demand, especially for the multimedia element; thus, traditional storage is no longer suitable to supports current requirements. Therefore, this study suggests the uses of cloud storage to encounter current demands that require rapid storage growth and dynamic concurrency demands. By integrating integration cloud technology into e-learning could share the unique characteristics of cloud such as elasticity, flexibility, efficiency, shareable and reliability. Besides, it provides several benefits such as flexibility in e-learning content, online course and perform learning activities at their own pace at any time and anywhere or ubiquitous environment [39].

\subsection{Instagram}

Lastly, this study proposed uses of reflective tools able to supports self-reflection components. Based on previous finding, [40, 41] most of literaute suggested the used of blog to supports self-reflection. However, in this study found out Instagram is preferable and suitable to supports self-reflection. According to the experts, Instagram and blog share the same fuctions. For example, create and develop content e.g insightful posts about own experience, thoughts or opinions, share video, links, documents and images. Learners express their thoughs in written form their developing own personal knowledge and criticality of knowledge creation as reflection of knowledge or contribution. Through comment section, learners would like to contribute, critiques, post inquiries, justification or clarification, peer could make comments on the posting. In the other hand, as mentioned in research by [41], indicated that the main problem by using blog was entering the blog. Learners had a low technological skill and their skills of critical reflection might also be low. Contracding with Instagram which more mainstream, friendly, on-demand access and learner have high technological skill toward instrgram. Thus, by using Instagram, it expected could reduce problem regard low technological skills. From creating personal profiles, to posting photos and videos, liking, and commenting, users have numerous chances to manifest their identities which help strengthen their belongingness to their communities.

\section{CONCLUSION}

This paper presents ICT-supported for participatory engagement within the e-learning community. The exploration and identifying suitable technology for participatory engagement involve the technology evaluation process. After the technology evaluation process was carried out, this study introduced a new selection of technology that expected to improve learners' engagemen by supporting interaction among learners and collaboration that much required in the e-learning community. As the results, ICT suggested are expected to change the current mindset to a participatory mindset such as active learning and producing learning content instead of being a consumer of learning content. Besides that, learning with different backgrounds of learners beneficial for learners to utilize the advantages of the to exchange knowledge, experience, and skills. It matters that 
various resources and more experienced community members (e.g., educators, experts) are supporting and available for the use of the learners. However, this study has a limitation whereby the study scope is limited to the case study in public universities in Shah Alam. Therefore, this research suggests expanding this study on other places such as private universities. Besides that, this study like to imply future recommendation is developing a prototype to validate the proposed ICT into the real-world to ensure this model is effective in improving and strengthen learner engagement. The development of ICT-supported models for participatory engagement within the e-learning community will help and encourage the interaction of learners within the e-learning community for engaging the learners more effectively, hence guarantee frequent interaction and continue usage of their learning in the future.

\section{ACKNOWLEDGEMENTS}

This work is supported by the Faculty of Computer and Mathematical Sciences, UiTM Shah Alam, Selangor, Malaysia and Research Management Institute (RMI) UiTM through Graduate Incentive Programme (GIP). [FILE NO:600-IRMI 5/3/GIP (046/2019)].

\section{REFERENCES}

[1] L. Jordan, "Transforming the Student Experiancen at a Distance: Designing for Collaboration Online Learning," Engineering Education, vol 4, no. 2, pp. 25-36, 2015.

[2] M. G. Moore, “Types of Interactions," American Journal of Distance Education, vol. 3, no. 2, pp. 1-7, 1989.

[3] M. Kurucay and F. A. Inan, "Examining the Effects of Learner to Learners Interaction on Sastisfaction and Learning in Online Undergraduate Courses," Computers \& Education, vol. 115, pp. 20-37, 2017.

[4] W. A. Cidral, et al., "Components \& Educations E-Learning Success Determinants: Brazilian Empirical Study," Computer \& Education, vol. 122, pp. 273-290, 2018.

[5] W. Farhan, et al, "E-learning system verses instructional communication tool. Developing and testing a new elearning user interface from the perspective of teacher and students," Technology in Society, vol. 59, p. 101192, 2019.

[6] Gutl, C. et al., "Expectations of the generation NeXt in higher education: Learning engagement approaches in information sciences subjects," 2015 International Conference on Interactive Collaborative Learning (ICL), Florence, pp. 205-214, 2015.

[7] F. Dingyloudi, "Value Creation: What Matters Most in Communities of Learning Practices in Higher Education," Studies in Educational Evaluation, vol. 62, pp. 209-223, 2019.

[8] P. Shea, “A Study of Students' Sense of Learning Community in Online Environments," Online Learning, vol. 10, pp 35-44, 2019.

[9] R. Yilman, "Knowledge Sharing Behaviour in E-learning Community Exploring the Role of Academic Self Efficacy and Sense of Community," Computers in Human Behavior, vol. 63, pp. 373-382, 2016.

[10] M. Boekaerts, "Engagement as an Inherent Aspects of the Learning Process," Learning and Instructions, vol. 43, pp 76-83, 2016.

[11] N. Bergdhal, et al., "Engagement, Disengagement and Performance When Learning with Techology in Upper Secondary School," Computers Educations, vol. 149, p. 103783, 2020.

[12] O. O. Mwambe and E. Kamioka, "EEG Cognition Detection to Support Aptitude-Treatment Interaction in ELearning Platforms," 2018 12th South East Asian Technical University Consortium (SEATUC), Yogyakarta, Indonesia, pp. 1-4, 2018.

[13] A. A. Taufiq, et al., "Effects of Success v Failure Cases on Learners-Learner Interaction," Computers \& Education, vol. 118, pp. 120-132, 2018.

[14] P. P. Paradez, et al., "Mobile Data Driven Language Learning: Affordance and Learner Perception," System, vol. 84, pp. 145-159, 2019.

[15] A. T. Korucu and A. Alcan "Different Between M-learning (mobile learning) and E-learning, Basic Terminology and Usage of M-Learning in Education," Porcedia-Social and Behavioral Sciences, vol. 15, pp. 1925-1930, 2011.

[16] K. Phirangee, "Students' Perceptions of Learner-Learner Interactions that Weaken a Sense of Community in an Online Learning Environment," Online learning, vo. 20, no. 4, pp. 13-33, 2016.

[17] Joharah A., "Investigating Role of Interactivtiy in Effectiveness of e-learning," PhD Thesis, College of Enginering Design Sciences Department of Computer Science, 2015.

[18] G. Marzano, et al., "Key Issues in Adult Non-Formal Participatory E-learning," Proceedings of the International Scientific Conference, vol. 6, pp. 69-79, 2016.

[19] C. McLoughlin \& M. J. W. Lee, "Social Software and Participatory Learning: Pedagogical Choices with Techology Affordances in the Web 2.0 Era," Proceedings Ascilite Singapore 2007, pp. 664-675, 2007.

[20] H. Vertianian, "Designing Participatory Learning," International Conferences on Educational Technologies 2014 and Sustainability, Technology and Education 2014, pp. 105-112, 2014.

[21] C. C. Liu, "A Participatory Learning Framework for Enhancing Children's Reading Experience with Electronic Book Readers," Research and Practice in Technology Enhanced Learning, vol. 8, no. 1, pp. 129-151, 2013.

[22] H. Haron, et al., "A Conceptual Model Participatory Engagement Within E-learning Community," Procedia Computer Science, vol. 116, pp. 242-250, 2017.

[23] J. C. C. Chen \& S. Kent, "Task engagement, learner motivation and avatar identities of struggling English language learners in the 3D virtual world," System, vol. 88, p. 102168, 2020. 
[24] B. Asnida, et al., "An Investigation of User Engagement Factors in E-Learning for Working Adults Learners," 2015 International Conference on Electrical Engineering and Informatics (ICEEI), Denpasar, pp. 633-637, 2015.

[25] S. Walji, et al., "Learning through engagement: MOOCs as an emergent form of provision," Distance Education, vol. 37, pp. 208-223, 2016.

[26] S. T. M. Kumar and S. K. Singh, "A Review of Social Media: In Future," Indonesian Journal of Electrical Engineering and Computer Science, vol. 8, no. 3, pp. 670-673, 2017.

[27] T. J. Dunn, et al., "Technology Enhanced Learning in Higher Education; Motivations, Engagement and Academic Achievement," Computer and Education, vol. 137, pp. 104-113, 2019.

[28] E. Emirli and A. A. Kurt, "Basic Competencies of Instructional Technologists," Procedia-Social and Behavioral Sciences, vol. 1, no. 1, pp. 998-1002, 2009.

[29] A. A. Abri "Comprehensive Classification of Collaboration Approaches in E-learning," Telematics \& Informatics, vol. 34, no. 6, pp. 878-893, 2017.

[30] J. Danish, et al., "On Activities and Affordances for Mobile Learning," Contemporary Educational Psychology, vol. 60, p. 101829, 2020.

[31] S. M. Sabri, et al., "Technology Evaluation to Support Knowledge Recall and Transfer," Proceedings of the 6th International Conference on Information and Education Technology, pp. 258-26, 2018.

[32] A. P. Rodriquez, at al., "Context-aware Mobile Learning System: Usability Assessment Based on a Field Study," Telematics and Informatics, vol. 48, p. 101346, 2020.

[33] G. J. Hwang, et al., "Effects of a Multi-level Concept Mapping- Based Questions-Posing Approach on Students' Ubiquitous Learning Performance and Perceptions," Computers \& Educations, vol. 149, p. 103815, 2020.

[34] Y. Sun, "A 2020 perspective on "How Live Streaming Influences Purchase Intentions in Social Commerce: An IT Affordance Perspective," Electronic Commerce Research and Applications, vol. 40, p. 100958, 2020.

[35] E. Ju, et al., "Impact Of Viewer Engagement On Gift-Giving In Live Video Streaming," Telematics and Informatics, vol. 35, no. 5, pp. 1450-1460, 2018.

[36] D. R. Alvarez, et al., "Mind the gap: Impact on Learnability of User Interface Design of Authoring Tools for Teachers," International Journal of Human-Computer Studies, vol. 94, pp. 18-34, 2016.

[37] M. Hamiz, et al., "Assessment Analytic Theoretical Framework Based on Learners' Continuous Learning Improvement," Indonesian Journal of Electrical Engineering and Computer Science (IJEECS), vol. 11, no. 2, pp. 682-287, 2018.

[38] Z. Zainudin, et al, "The Roles of Ganified E-Quizzes on Student Learning and Engagement: An interactive Gamification Solution for A Formative Assessment System," Computers \& Education, vol. 145, p. 103729, 2020.

[39] J. K. R Sastry \& M. T. Basu, "Securing SAAS Service under Cloud Computing Based Multi-Tenancy Systems," Indonesian Journal of Electrical Engineering and Computer Science (IJEECS), vol. 13, no. 1, pp. 65-71, 2019.

[40] H. Zou, et al., “ Think About How Fascinating This is Engagement in Academic Blogs Accros Displine," Journal of English for Academic Purposeses, vol. 43, p. 100809, 2020.

[41] K. Kalk, et al., "The Characteristics of Students, Blog Groups and Blogging that Predict Reflection in Blogs During Teaching Practice and Induction Year," Teaching and Teacher Education, vol. 86, p. 102900, 2019.

\section{BIOGRAPHIES OF AUTHORS}

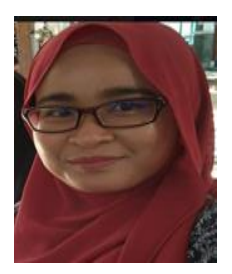

Noor Hida Natrah is a PhD student at the Faculty Computer and Matematical Sciences, Universiti Teknology Mara, (UiTM), Shah Alam. She received a Bachelor degree in Computer Science from Kolej Poly-Tech Mara collaborate with Conventry University, Kuala Lumpur and received her master degree in Computer Science from University Teknology Mara (UiTM) in 2014. Her research interests include Knowledge Mangement, Participatory Learning and E-learning.

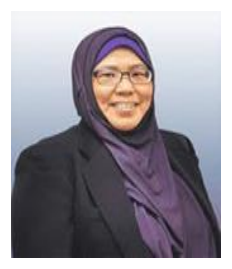

Prof Dr Haryani Haron is Dean at the Faculty Computer and Matematical Sciences, Universiti Teknology Mara, (UiTM), Shah Alam. She received a Bachelor degree in Computer Science from Arkansas State University, USA in 1986 and master degree in in Computer Science from University of Teknology Malaysia (UTM) in 1996. She was conferred with a PhD. in Computer Science from University Teknology Malaysia (UTM), in 2009. Her research interests include Knowledge Management, Knowledge Management Systems, Information Systems research and IT Governance.

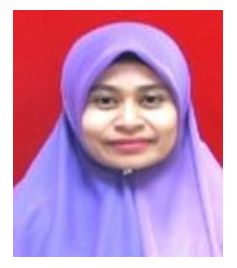

Dr. Afdallyna Fathiyah Harun currently is a senior lecturer at at the Faculty Computer and Matematical Sciences, Universiti Teknology Mara, (UiTM), Shah Alam She holds a bachelor's degree in Information System Engineering, Universiti Teknologi MARA Malaysia, 2005, and a master's degree by research in Information Technology, Universiti Teknologi MARA Malaysia, in 2008. She was conferred with a PhD from University of Nottingham, UK, 2014. Her research areas include User Experience, Human Centered Informatics, Design Thinking, Technology Appropriation and Interaction Design. 